\title{
LOS MURALES DE CARLOS MÉRIDA. RELACION DE UN DESASTRE
}

\section{LOUiSE NOELLE}

El movimiento artístico conocido como muralismo mexicano ha logrado, tanto nacional como internacionalmente, un amplio reconocimiento, y son de todos conocidos los tres principales exponentes, Diego Rivera, José Clemente Orozco y David Alfaro Siqueiros, que llevaron esta propuesta a sus máximas expresiones. No obstante, es preciso considerar dentro de esta corriente a otros artistas, no sólo a aquellos que emularon a los maestros, sino también a los que supieron aportar una expresión diferenciada en su forma mas no en el fondo. Éste es el caso de Carlos Mérida, que compartió con los muralistas sus principales preocupaciones, como la de realizar una obra eminentemente nacional y que expresara los valores autóctonos tanto en su aspecto como en su espíritu, así como la búsqueda de una adecuada realización técnica, y la correcta colocación y proporción del mural con respecto al espacio arquitectónico.

Las propuestas acertadas de Mérida en el problema de la integración con la arquitectura y en la búsqueda de una identidad permiten incluirlo dentro de este movimiento, y esto queda patente al realizar una revisión de su producción mural y del contexto en que ésta se realiza. Sin embargo, quien se avoque a esta tarea y trate de estudiar personalmente sus obras murales se encontrará con la triste realidad de que éstas se encuentran destruidas en su mayoría. Las circunstancias de estos estragos han sido diversas a lo largo de casi cuarenta años en que el artista realizó su obra pública en México, pero en todos los casos resulta deplorable. Las proposiciones formales originales obtuvieron una realización técnica novedosa, que buscaba su permanencia en la utilización de materiales modernos, vinílicos, concreto y plásticos, y en muchos casos fueron ejemplos pioneros. Así su creatividad queda patente, por lo que es imprescindible buscar y conservar ahora los diversos documentos que permitan reconstruir y valorar la obra mural de este artífice, puesto que forma parte de la historia del arte contemporáneo mexicano.

Carlos Mérida nació en la ciudad de Guatemala el 2 de diciembre de $1891,{ }^{1}$ y sus inicios dentro del campo del arte fueron por el camino de la

1 Este dato biográfico, al igual que muchos de los que aparecen a continuación, están tomados ptincipalmente del libro de Luis Luján Muñoz, Carlos Mérida, Cuadetnos de 
música; sin embargo, una incipiente sordera lo indujo a cambiar el piano por los pinceles. ${ }^{2}$ Por ese tiempo, comienza a frecuentar las tertulias que con marcado sesgo intelectual organizaba en la ciudad capital Santiago González, a las que concurrían un grupo de jóvenes artistas como Carlos Valenti (1884-1912) y Agustín Iriarte (1876-1962), entre otros; para 1909 muere este preceptor y toma su puesto de guía Jaime Sabartés, un catalán que había llegado al país centroamericano en 1904, instalando un comercio en la ciudad de Guatemala. Las reuniones tienen entonces lugar en la trastienda de este negocio, donde Mérida y sus amigos entran en contacto personal por primera vez con pinturas modernas, cuadros y retratos debidos a Pablo Picasso, amigo personal de Sabartés. ${ }^{3}$ A él se debe el estímulo para que Mérida realizara su primera exposición en Guatemala en 1910, y que emprendiese con Carlos Valenti, en 1912, un viaje a París amparados por una carta de presentación a Picasso.

El viaje a Europa lo pone en contacto con las vanguardias artísticas, en especial al frecuentar los talleres de Amadeo Modigliani, Kess Van Dongen y Hermenegildo Anglada Camarasa. ${ }^{4}$ Asimismo sufte la fuerte impresión del suicidio de su amigo Valenti, iniciando así una serie de viajes para reponerse. En 1914 regresa a su patria acompañado del escultor guatemalteco Rafael Yela Gunter, con quien le liga toda una serie de intereses comunes. Estos dos artistas inician entonces un movimiento de revaloración de lo indígena, a través de sus diversas expresiones plásticas. ${ }^{5}$ Se trata de una preocupación por recuperar, no los elementos folklóricos, sino más bien la esencia propia de los valores locales y de alguna manera también lo prehispánico; lo que se traduce en una exposición en Guatemala en 1919 , otra en México en 1920 y en obras posteriores, como el portafolios de esténciles con temas guatemaltecos que presenta en París en 1927. De esta época provienen los que habrán de ser los rasgos distintivos de su

Tradición Guatemalteca, Guatemala, 1985, que contiene gran número de documentos y fotografías sobre la vida del pintor; asimismo, estas informaciones se encuentran en diversos trabajos monogtáficos mencionados en la bibliografia

2 Margarita Nelken, Carlos Mérida, UNAM, México, 1961, p. 27. Tal vez esta influencia temprana de la música se refleja posteriormente en el ritmo de sus pinturas, como lo apunta Xavier Moyssén en el texto del catálogo Diseños de Carlos Mérida. Galería Atvil, México, 1981, p. 6

3 Ver el libro de Luis Luján Muñoz, Jaime Sabartés en Guatemala: 1904-1907, Dirección General de Cultura, Bellas Artes, Guatemala, 1981.

${ }^{4}$ Para una descripción in extenso de estas influencias, ver Margarita Nelken, op cit , p. 28 .

"Luis Cardoza y Aragón, en su libro Carlos Mérida, Ediciones de la Galetía Literaria, Madrid, 1927, se refiere a Carlos Mérida como uno de los primetos artistas que dieron atención a los indigenas con un impulso modenno, dejando de lado el pintoresquismo. 
producción posterior: búsqueda de la abstracción geométrica, basada implícitamente en la producción plástica maya, intensidad en el colorido plano y bien delimitado, influido por su acercamiento a lo autóctono, diseños estáticos derivados de su aprendizaje europeo, una muy personal elegancia y buen gusto en la expresión donde la figura humana es primordial.

El artista guatemalteco llegó a México en el momento crucial del desarrollo artístico del movimiento muralista, participando en esta primera efervescencia; para 1922 es ayudante de Diego Rivera en el mural La creación, en el Anfiteatro Bolívar. En este momento las ideas de Mérida comulgaban de alguna manera con las de Rivera, influido por José Vasconcelos y sus planteos sobre la supremacía del mestizaje y del americanismo. ${ }^{6}$ Sin embargo, la ausencia de una militancia en los partidos de izquierda, así como el no haber tomado parte en la Revolución Mexicana, lo alejaron de los núcleos iniciales del movimiento muralista; esta actitud que rehúye todo compromiso político y de arte oficial, tanto como su estilo y temática, harán de él, en los años cuarenta, un miembro de las vanguardias que se enfrentan a la "Ruta única" de la plástica revolucionaria, convirtiéndose en uno de los precursores de las jóvenes generaciones de artistas.

También es importante apuntar que durante su primer periodo en México, Carlos Mérida colaboró con Manuel Gamio en los trabajos arqueológicos de Teotihuacan; esta relación debe de haber reafirmado en el artista su convencimiento de que las expresiones prehispánicas no sólo eran objeto de estudio de la antropología, sino también del arte. En efecto, Gamio había demostrado en un libro temprano las cualidades artísticas de los objetos precolombinos, aunque el pionero en este sentido fue Manuel G. Revilla al expresar que "nuestros monumentos antiguos... (tienen) rasgos de belleza. . . para quien busque en ellos el arte, aparecerán como un libro escrito en idioma universal"?

Asimismo es fundamental saber que este pintor, a pesar de haber sentado sus reales en México desde 1920, donde muere el 21 de diciembre de 1984, conservó siempre su nacionalidad guatemalteca; este hecho, si bien puede parecer irrelevante en cuanto a sus expresiones artísticas, jugó un papel muy importante tanto en la falta de asimilación a los grupos de

\footnotetext{
"Estos conceptos se encuentran expresados en el texto "El mestizaje" del libro de José Vasconcelos, La raza cósmica, Espasa Calpe, México, 1948 "Todo para indicar que llegaremos en América. . a la creación de una raza. . la Raza Cósmica", p. 53.

${ }^{7}$ Ver el libro de Manuel G. Revilla, El arte en México, Portúa Hermanos, México, 1923. Segunda edición, p. 27. La primeta edición fue en 1892 En el significativo libro de Manuel Gamio, Forjando patria, Editorial Portúa, México, 1916, es de especial interés el capitulo X, "El concepto del arte prehispánico"
} 
artistas militantes, como a la imposibilidad de defender sus obras como patrimonio artístico nacional. Así, puesto que la Ley Federal sobre Monumentos y Zonas Arqueológicas, Artísticas e Históricas, 1972, no contempla la protección de las obras de arte de los extranjeros, se explica en parte la bárbara destrucción que se ha hecho, a través de los años, de la obra pública de Mérida en México.

Dentro de su desarrollo artístico, en 1927 realiza un nuevo viaje a París, donde entra en contacto con varios artistas, lo que se traduce en el abandono en su estilo de los elementos indigenistas, conservando sin embargo el color y los temas, una liga que siempre mantuvo con sus raíces. Sus principales relaciones, por entonces, son con Pablo Picasso, Wassily Kandinsky, Joan Miró, Paul Klee y Joaquín Torres García, que constituyen notorias influencias en los campos del geometrismo, el surrealismo y el constructivismo universal. ${ }^{8}$ Por lo que se refiere al pintor uruguayo, presenta no sólo una repercusión en Mérida, sino que ambos tienen asimismo una serie de conceptos paralelos en su producción posterior; en ellos es común la expresión geométrica, la búsqueda del universalismo sin abandonar sus lazos americanos, y el uso constante de algunos símbolos, que en el guatemalteco se reducen principalmente al hombre. En realidad los dos artistas pueden suscribir lo afirmado por Torres García, "el arte que, apoyado en tales conceptos universales, puede llegar a una verdadera construcción en la que todo le sea comprendido. $\mathrm{Y}$ tal concepto, es idéntico al de la cultura. Por esto, tal arte es el que sólo puede responder a la necesidad de un pueblo para poseer una verdadera cultura". 9

A su vuelta a México, la producción de Carlos Mérida oscila entre el surrealismo y la abstracción, destacando en él sus cualidades de gran dibujante y de excelente colorista, a la vez que utiliza indiscriminadamente técnicas y materiales plásticos novedosos. Es a partir de 1940 que su expresión se vuelve geométrica por excelencia, con colores claros y líneas rectas que se entrecruzan y delimitan con precisión las diferentes áreas iluminadas que toman su valor del contraste; para 1950 establece este estilo que conservará con variantes hasta su muerte y que, además de las constantes antes expresadas, tiene su inspiración en la temática prehispánica, basándose en textos y códices, en especial en el Popol-Vuh. En este periodo aparecen el ritmo y la proporción en sus obras, la influencia de

\footnotetext{
${ }^{8}$ Xavier Moyssén, "Tamayo, Métida, Paalen y Gerszo", Historia del arte mexicano, Salvat, México, 1982, vol. XI, p. 84.

9 Joaquín Torres García, Universalismo constructivo, Editorial Poseidón, Buenos Aires, 1944 , p. 342
} 


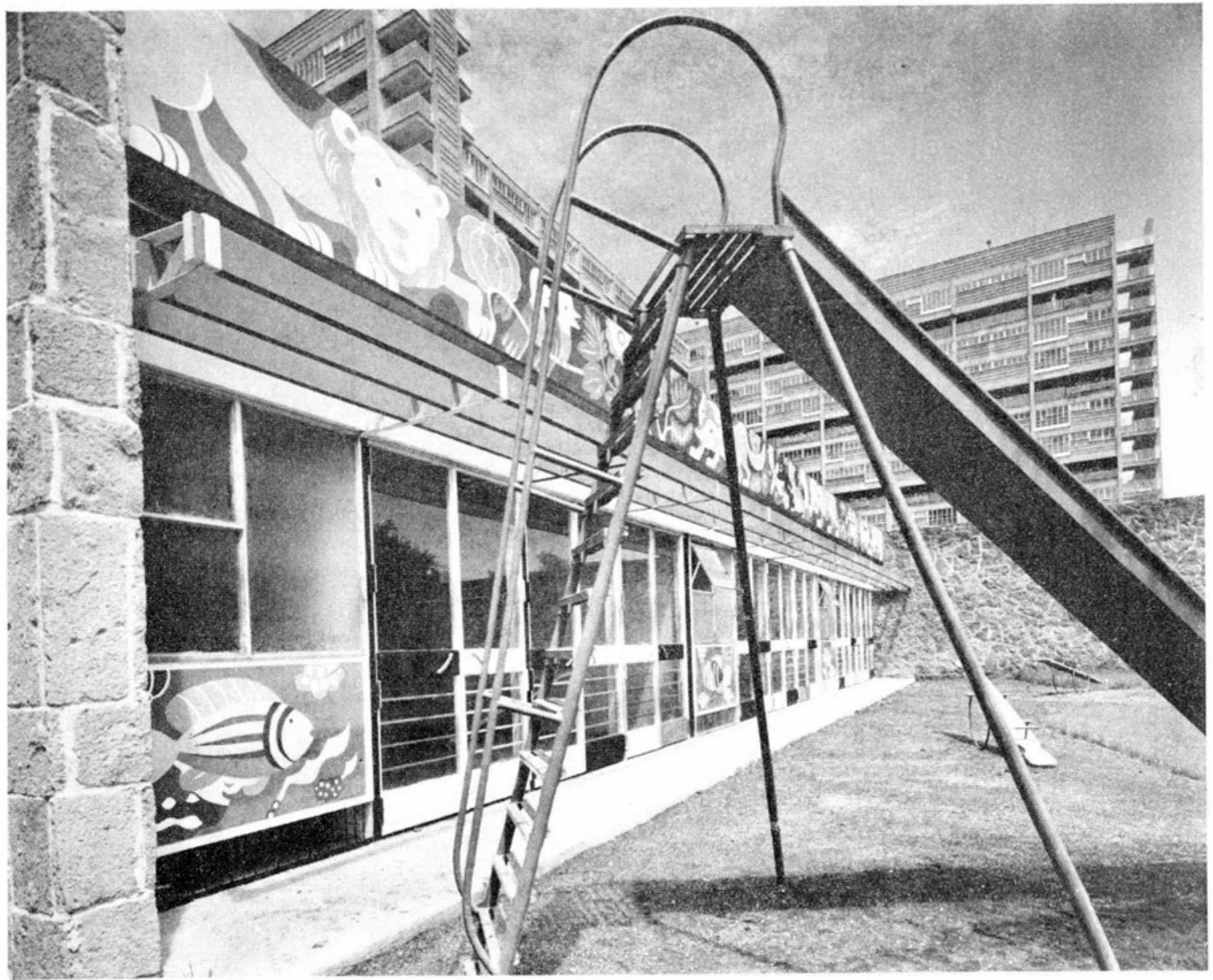

Figura 1. Multifamiliar Presidente Alemán, arquitecto Mario Pani. Guardería Infantil, 1949. Friso de vinílica sobre concreto, actualmente destruido. 1949 (foto Zamora). 


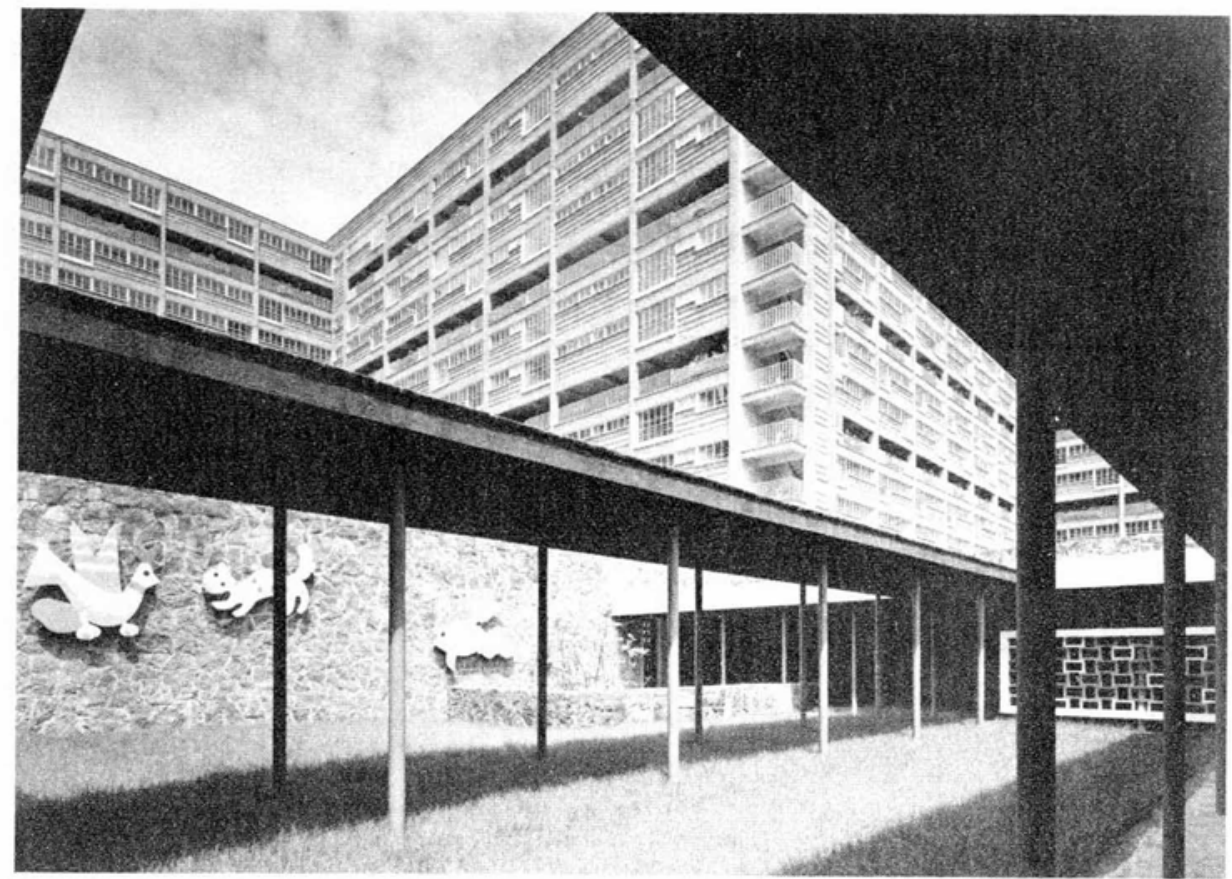

Figura 2. Multifamiliar Presidente Alemán, arquitecto Mario Pani. Guardería Infantil, 1949. Motivos zoomorfos de vinílica sobre concreto. La foto superior (foto Zamora) los muestra en la época de su realización, y en la foto inferior (foto María García) se aprecia que tan sólo queda una figura. 1949.

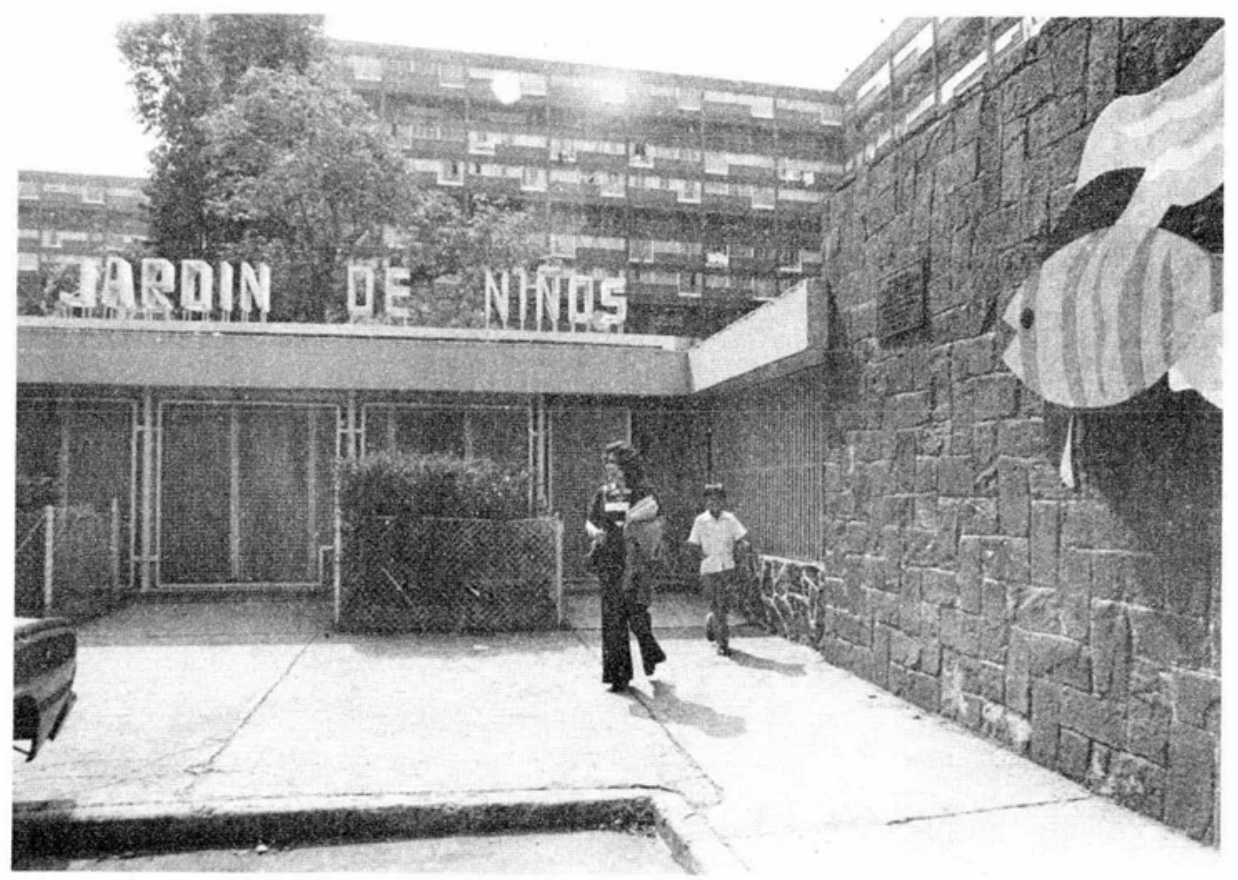




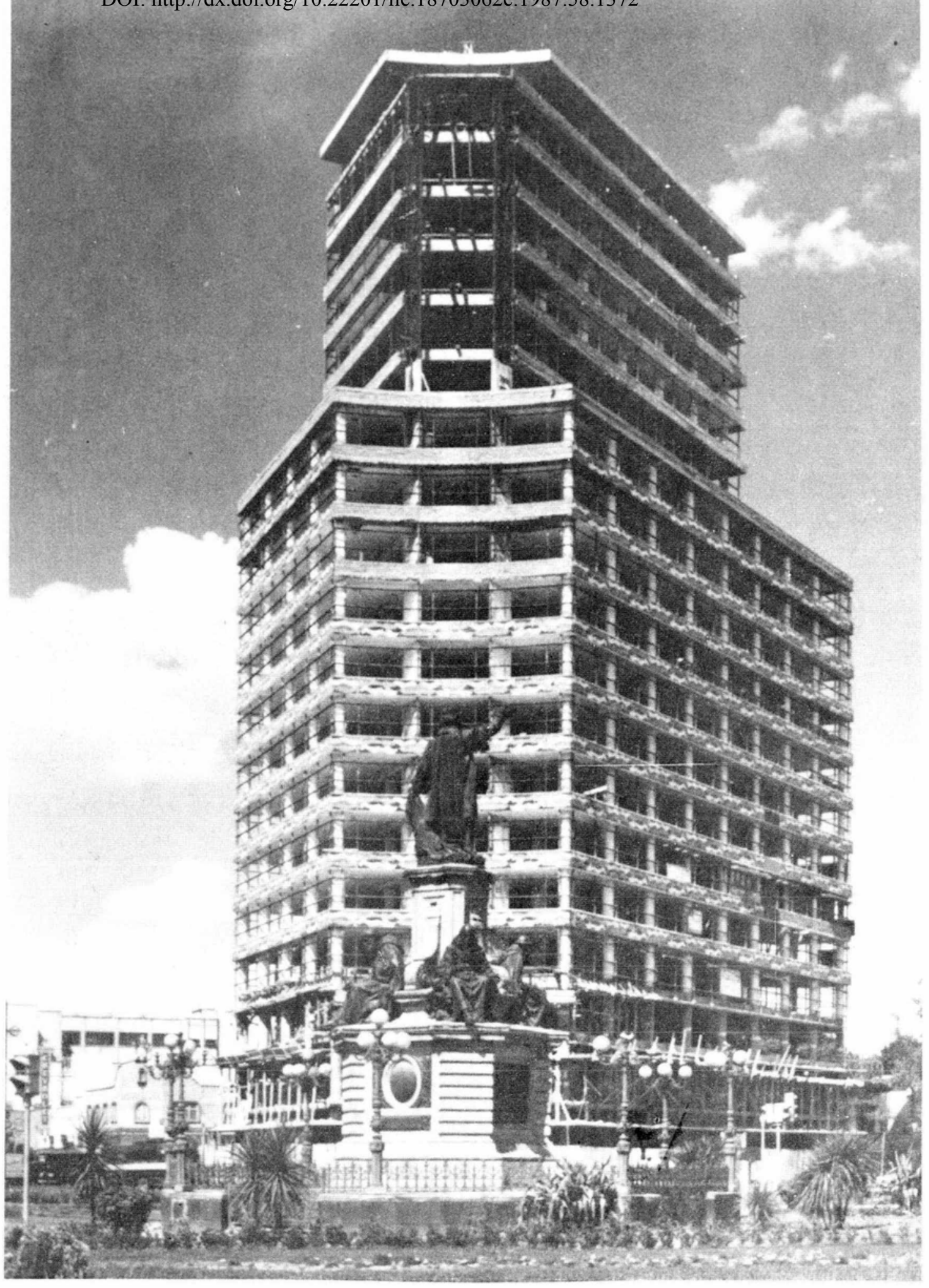

Figura 3. Edificio de Recursos Hidráulicos de los arquitectos Mario Pani y Enrique del Moral, 1952. En esta foto se ve el edificio con las platabandas de mosaicos de metal esmaltado en proceso de colocación; poco tiempo después fueron retiradas. 


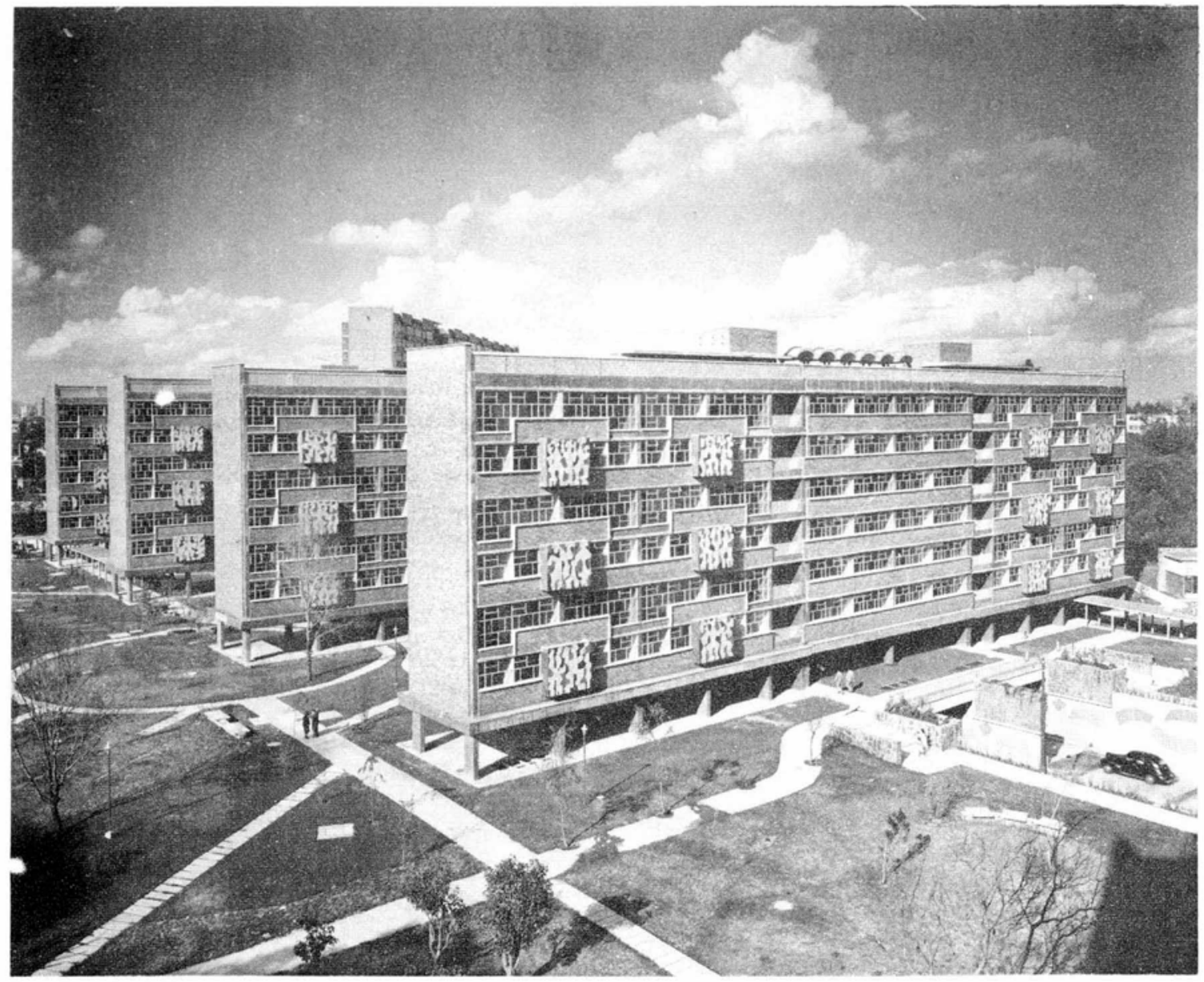

Figura 4. Multifamiliar Presidente Juárez, arquitectos Mario Pani y Salvador Ortega, 1952. Aspecto de los edificios de seis pisos con los paneles de relieves en concreto que recubrían los closets y, a la derecha, parte de la decoración del paso a desnivel; algunos de estos edificios sobrevivieron al sismo de 1985 (foto Zamora). 


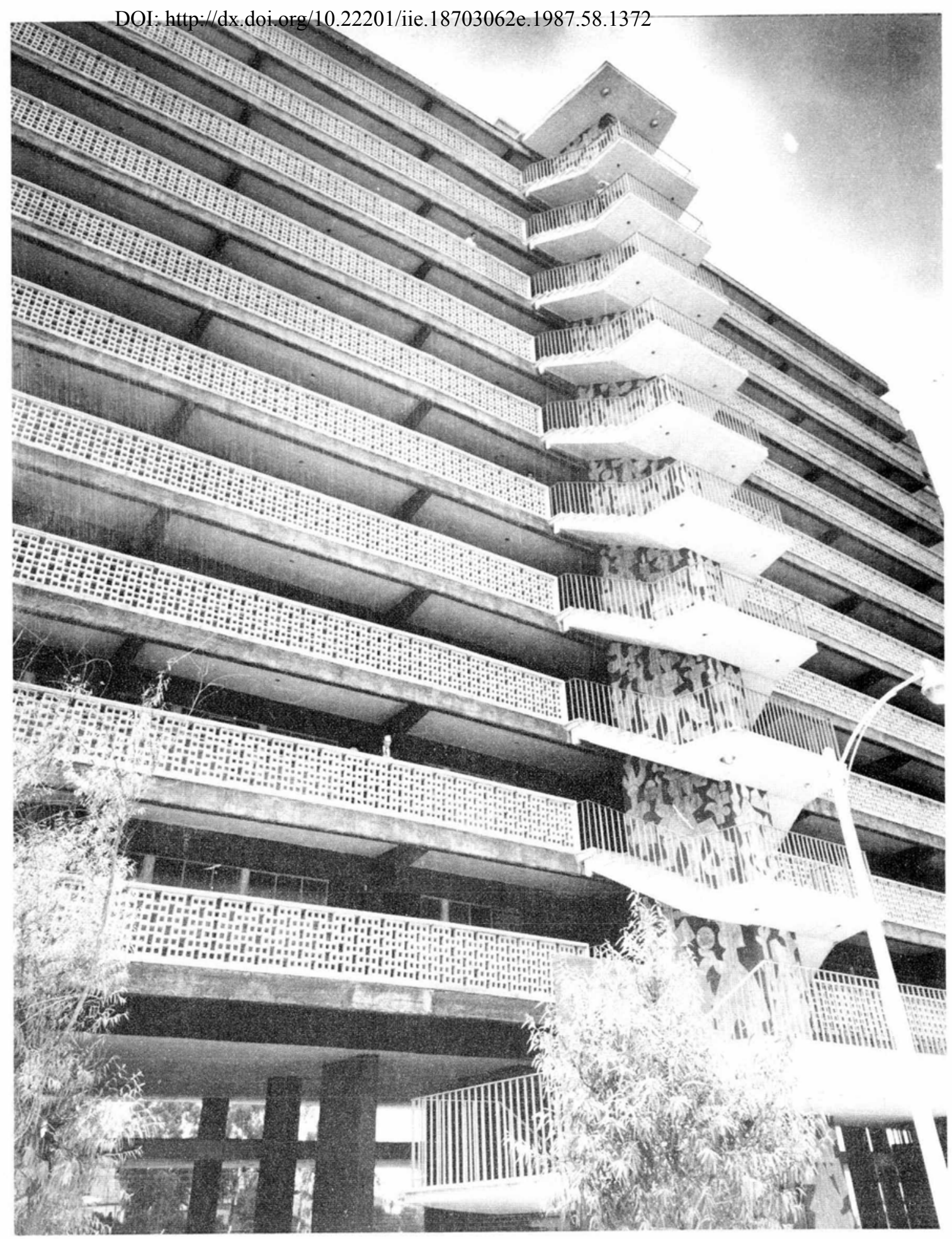

Figura 5. Multifamiliar Presidente Juárez, arquitectos Mario Pani y Salvador Ortega, 1952. Edificio de diez pisos con la escalera decorada con relieves en concreto policromado al frente. Estos edificios, cinco en total, fueron demolidos a consecuencia del sismo de 1985 (foto Zamora). 


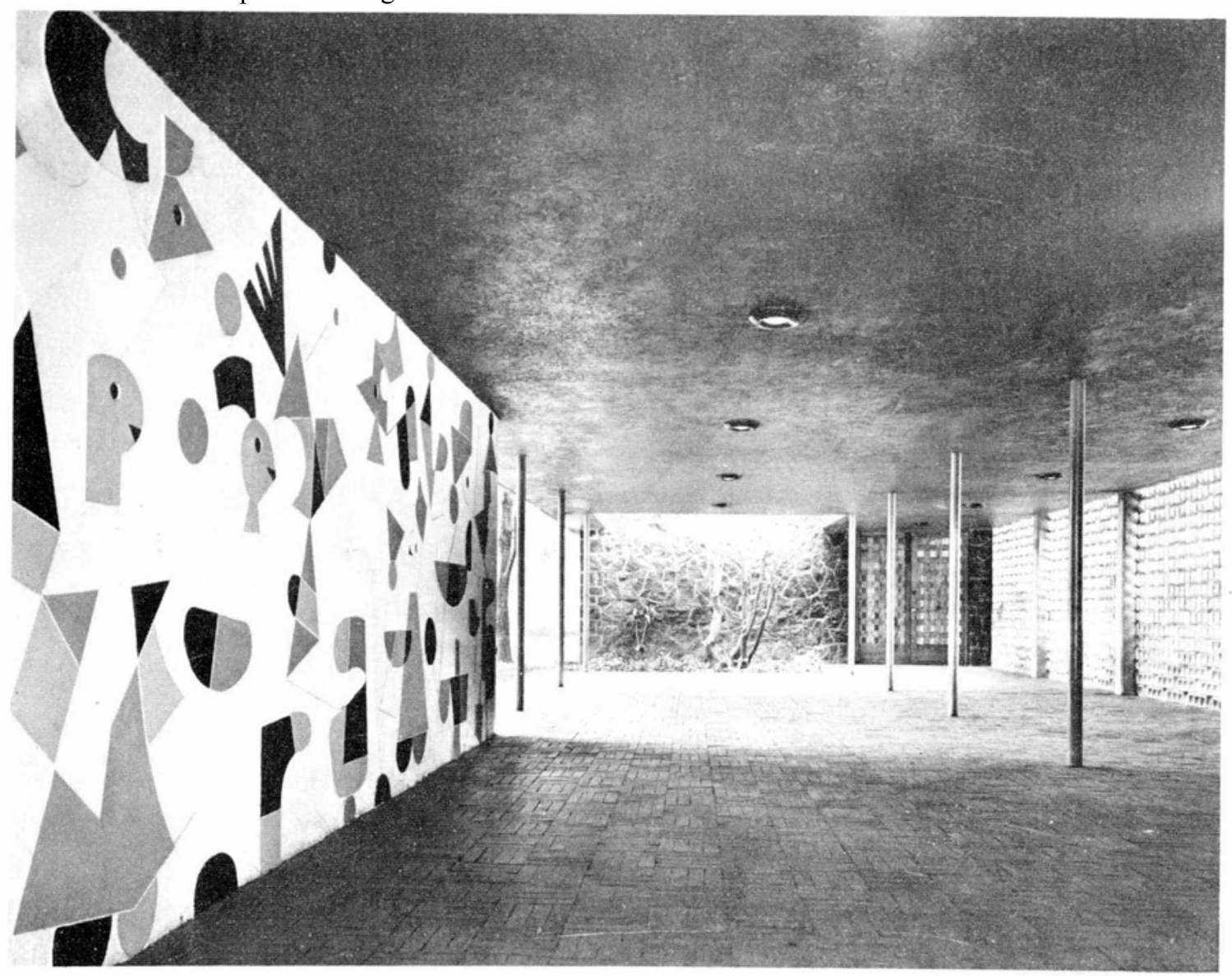

Figura 6. Multifamiliar Presidente Juárez, arquitectos Mario Pani y Salvador Ortega, 1952. "Juego de niños" en la Guardería infantil, cuyo relieve en concreto policromado se haya muy bien conservado (foto Zamora). 


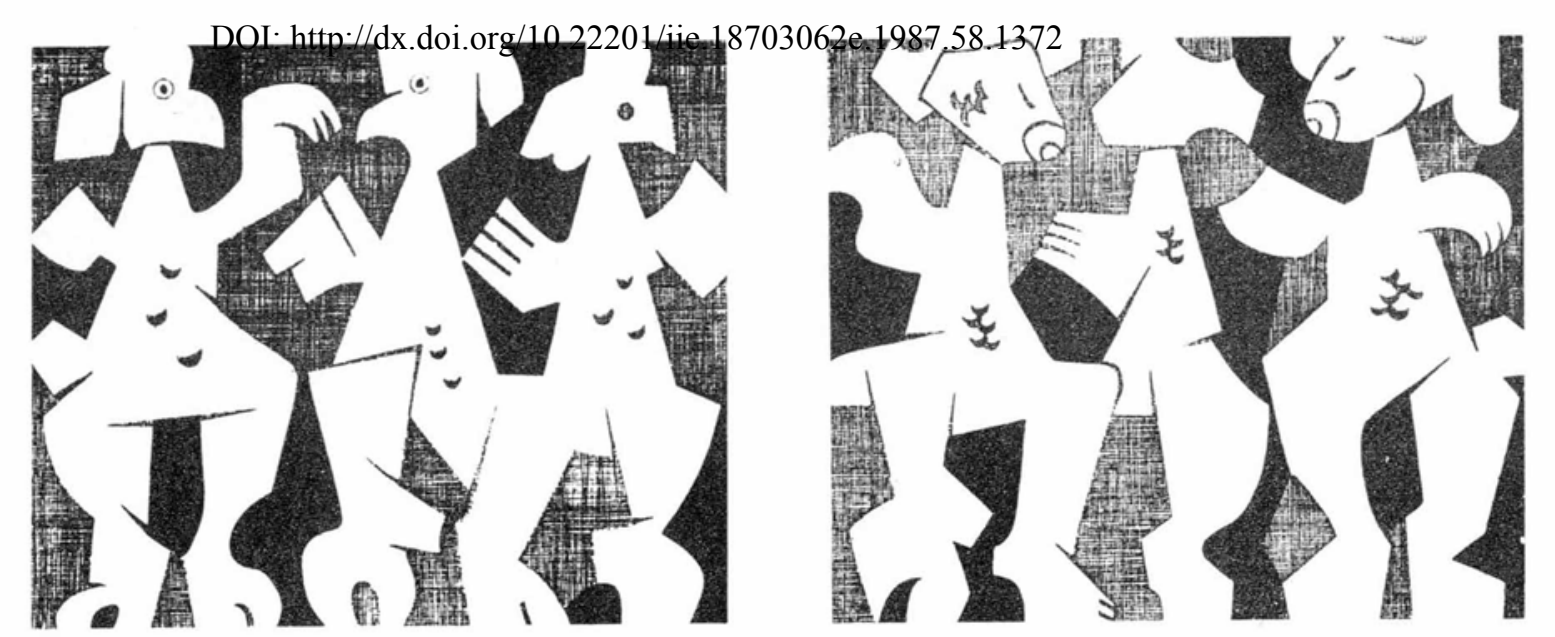

A.

B.

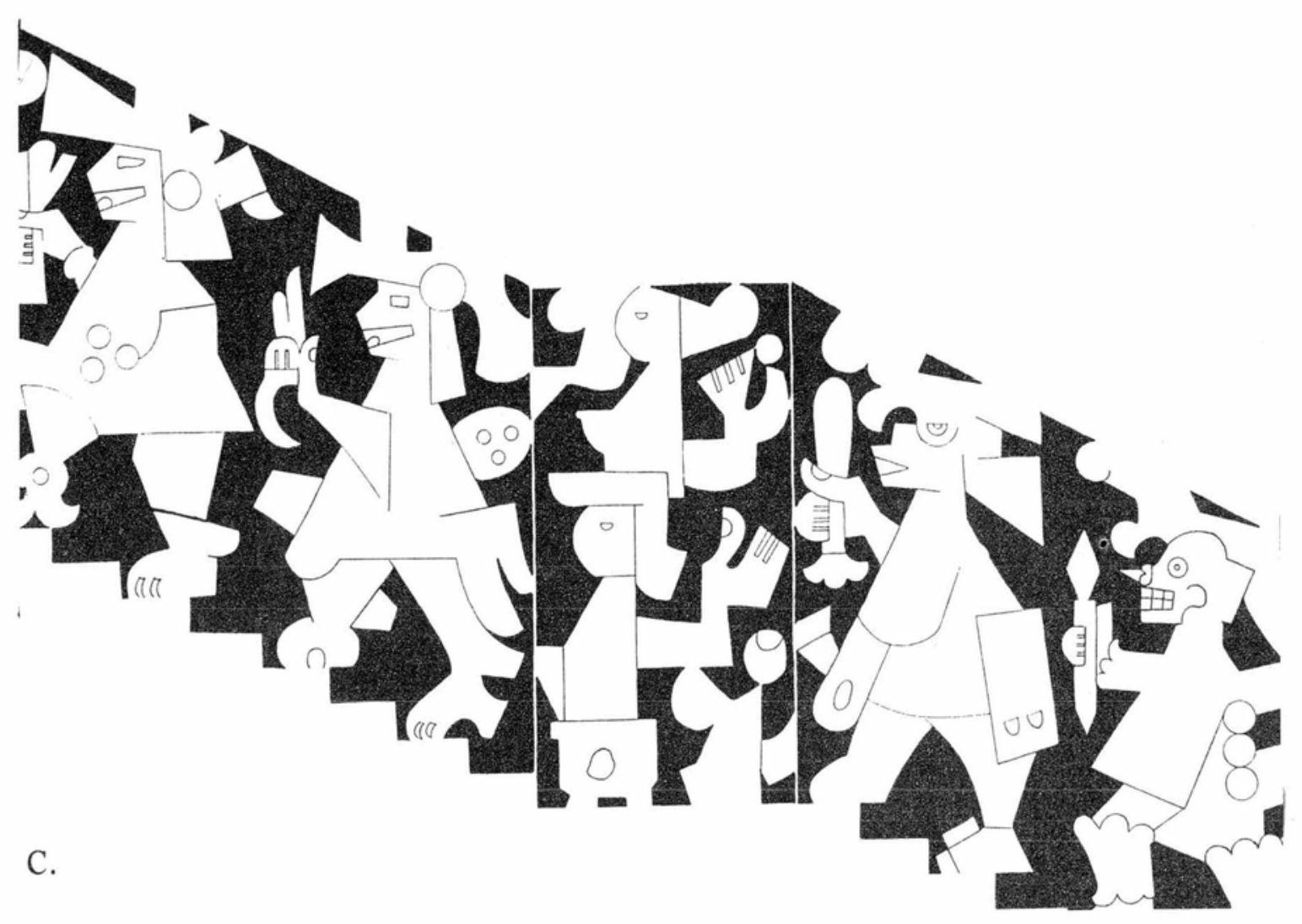

Figura 7. Diseños de Carlos Mérida para las decoraciones del Multifamiliar Presidente Juárez, 1952. A. El tercer cuadrante de la leyenda Mexica de los cuatro soles, el sol de fuego (Xiuh-Tonatiuh) a cuyo término los hombres se convirtieron en pájaros. B. El cuarto cuadrante de la leyenda mexica de los cuatro soles, el sol del agua (Atonatiuh), a cuyo término los hombres se convirtieron en peces. C. Detalle de la decoración de las escaleras exteriores basado en la leyenda del principio del mundo según la "Relación de Texcoco". 


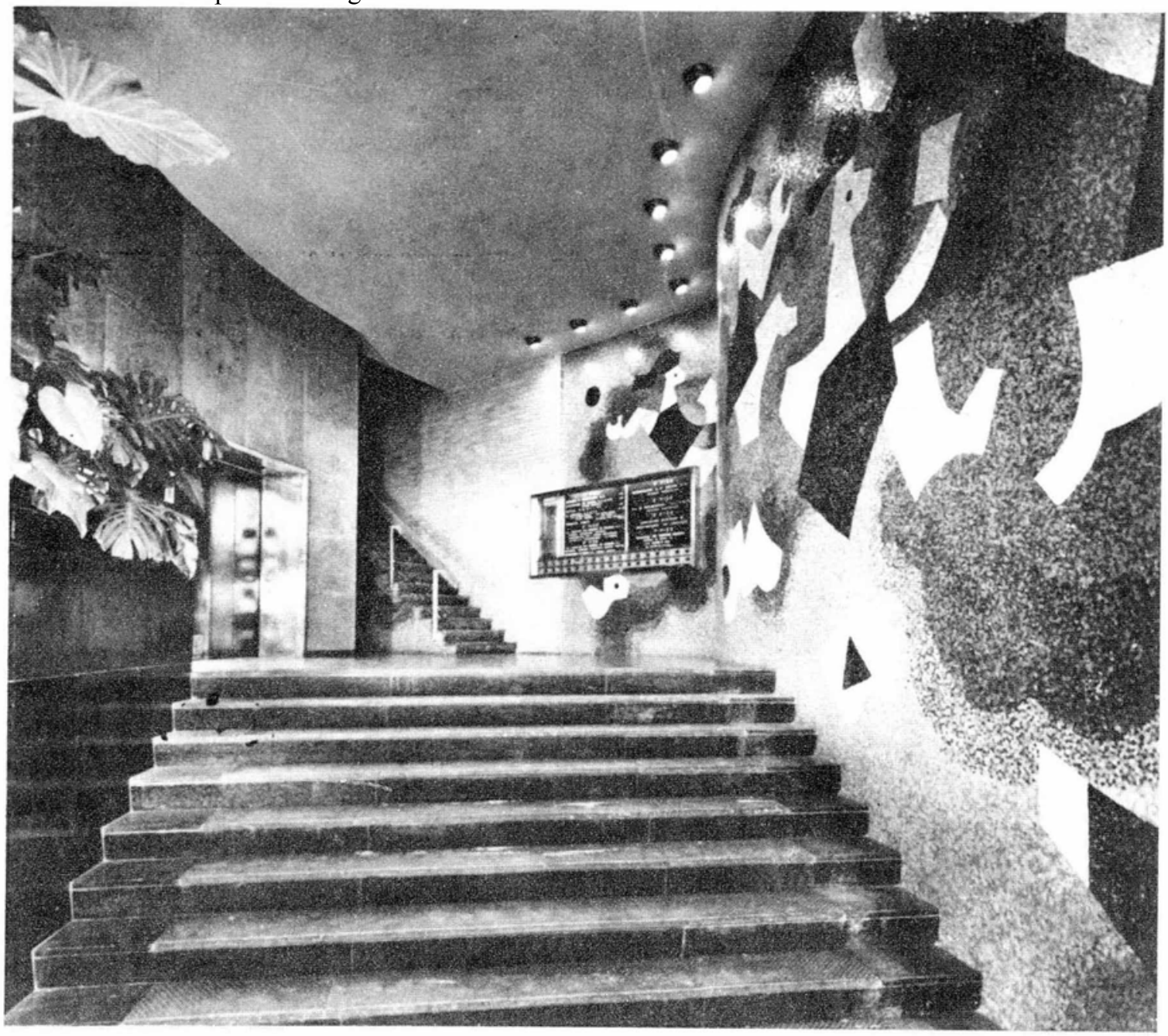

Figura 8. Edificio Reaseguros Alianza, arquitecto Enrique del Moral, 1953. Decoraciones de mosaico veneciano en el vestíbulo, actualmente conservadas en la Galería Arvil (foto Zamora). 


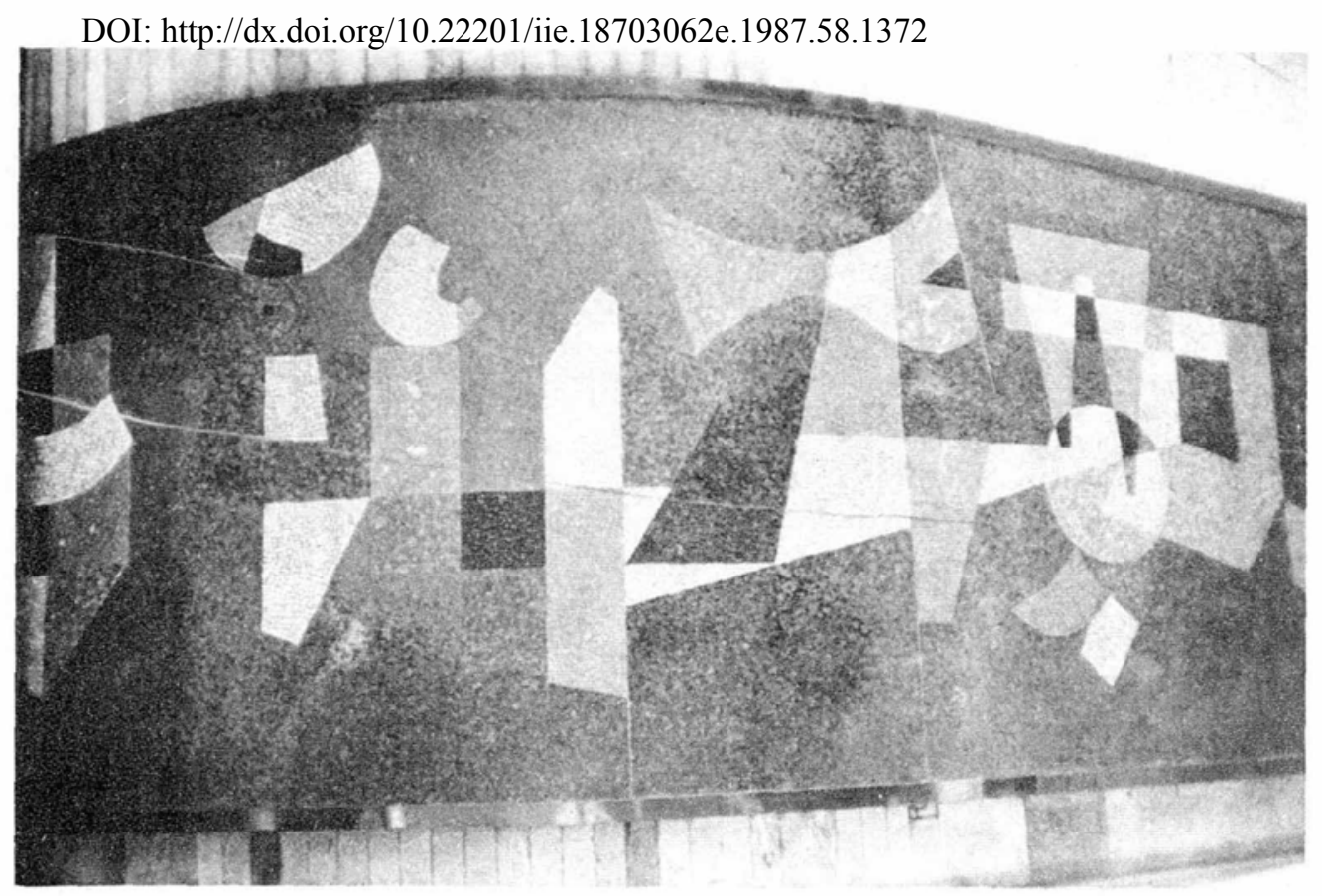

Figura 9 A. Edificio de Crédito Bursátil, arquitecto Guillermo Struck, 1955. Mural de mosaico veneciano al exterior con prolongación en el vestíbulo.

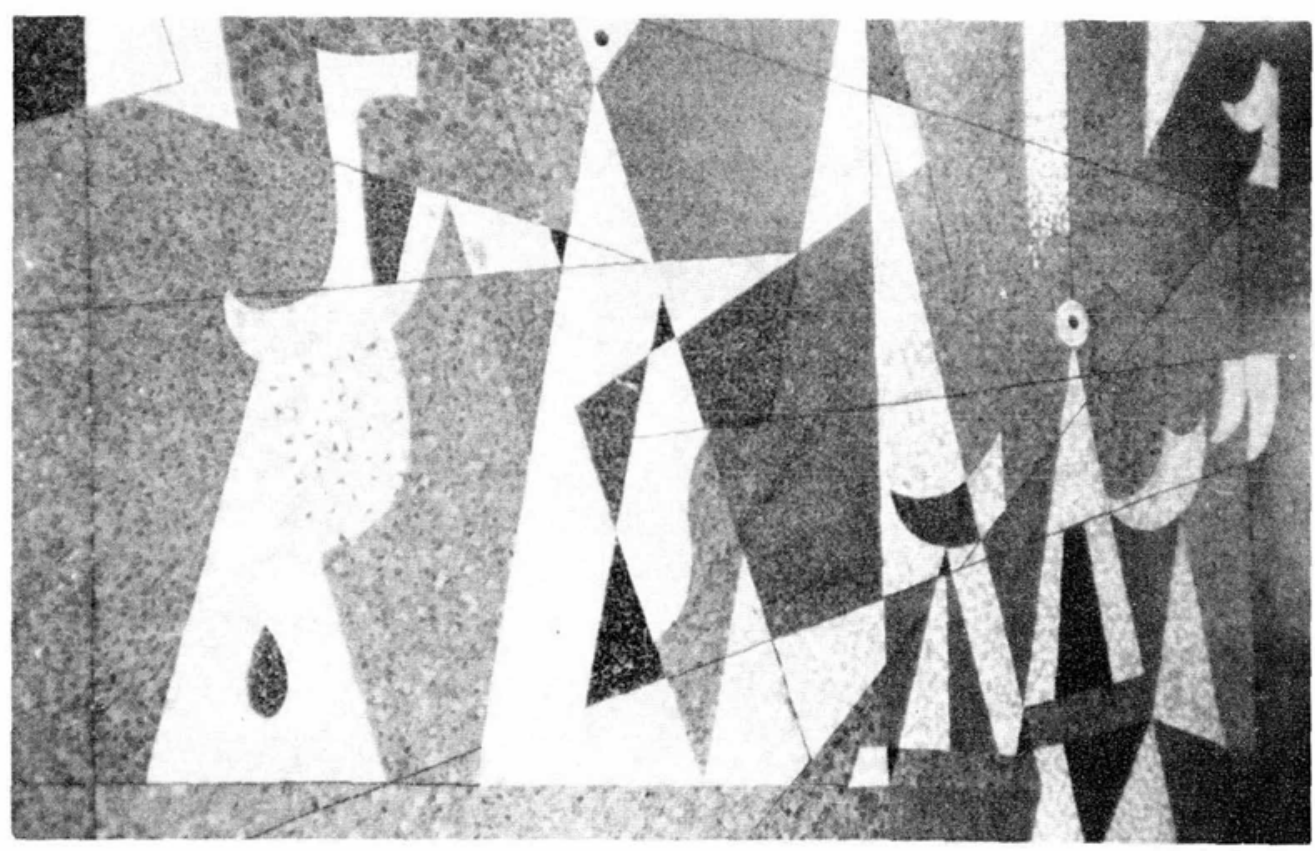

Figura 9 B. Banco de Fomento Cooperativo, arquitecto Enrique del Moral, 1958. Mural de mosaico veneciano en el vestíbulo. 


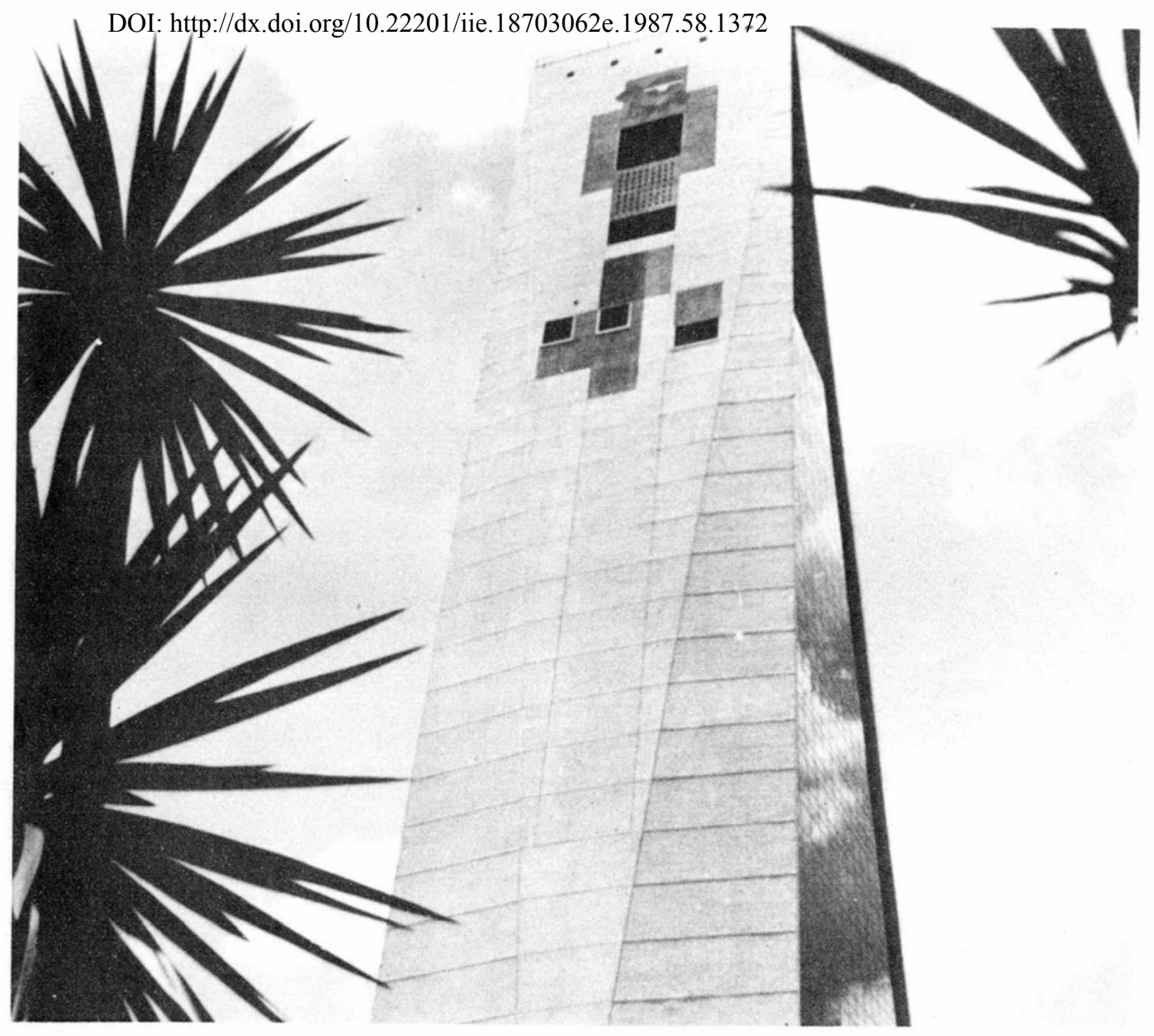

Figura 10. Torre Banobras, arquitecto Mario Pani y Asociados, 1964. Aspecto de la torre cuando aún tenía la decoración "Motivos tlatelolcas". 


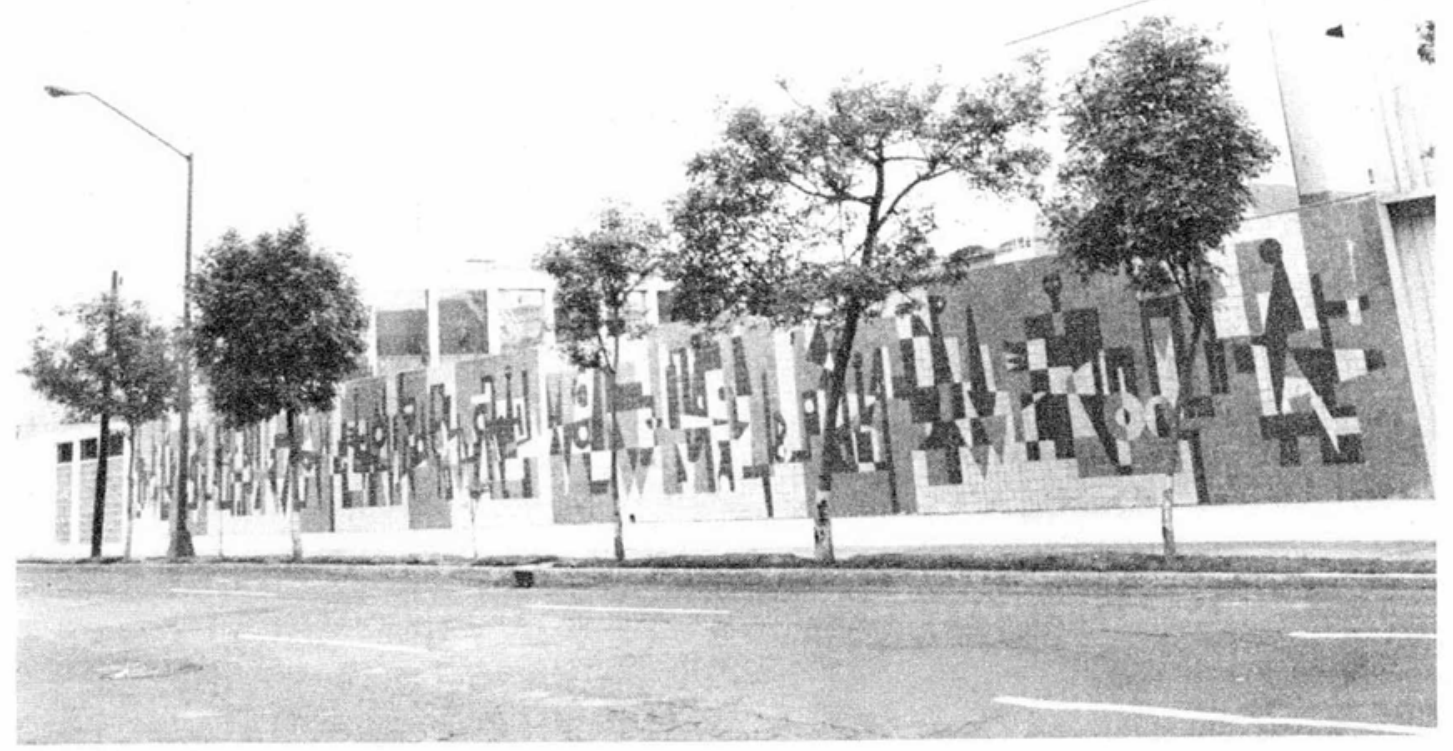

Figura 11. Fábrica de Bujías Champion, Vallejo, 1967. Mural en mosaicos poblanos, donado a la UNAM en marzo de 1987. Aspecto general de la parte exterior y un detalle del interior (fotos Lourdes Almeida).
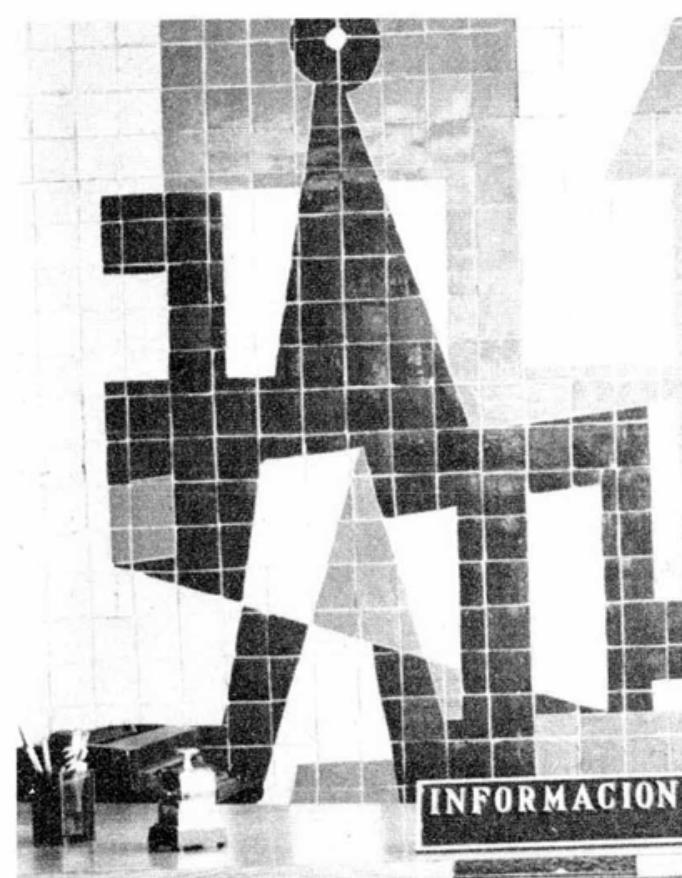


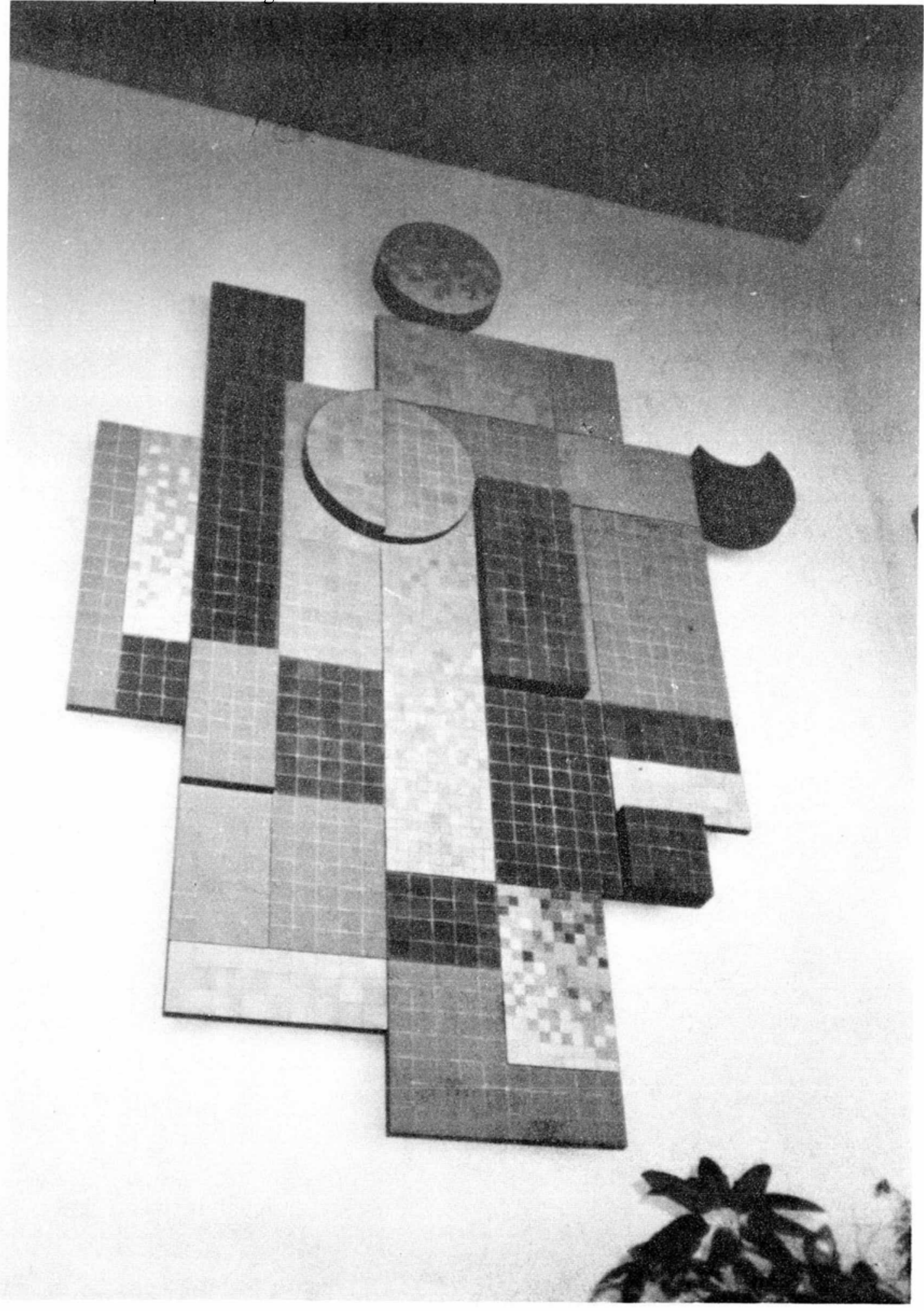

Figura 12. Edificio Omega, arquitecto Pedro Ramírez Vázquez, 1985. Decoraciones en mosaico montadas en marcos metálicos. Detalle. 
la música, la danza y la arquitectura. ${ }^{10}$ Asimismo en esta época 1937-1943 se localizan sus colaboraciones con Frances Toor, ilustrando algunas de sus publicaciones como Mexican Folkways, o escribiendo sobre los muralistas y sus obras en pequeños libros que publicara esta editora; aquí queda comprobado su interés por el muralismo mexicano y su adhesión a este movimiento en el campo de la práctica. ${ }^{11}$

Es también en este momento cuando Mérida entra en la madurez y culminación de su carrera, retornando al muralismo, pero en esta ocasión dentro de sus propios enunciados ${ }^{12}$ e insertado dentro del movimiento arquitectónico conocido como la integración plástica. Así asevera, entre otras cosas, que "El viejo concepto del muralismo mexicano (Montenegro, Rivera, Siqueiros, Orozco) ha dejado ya de ser. . la pintura hay que fundirla en el cuerpo arquitectónico y no tomarla como mera ornamentación. Éste es el muralismo que avizoramos". ${ }^{13}$

Conviene aquí analizar el renovado cuestionamiento sobre la integración plástica; si bien éste es el título con que se ha bautizado una tendencia que floreció hacia mediado del siglo XX en la arquitectura mexicana, en realidad sólo se proponía la conjunción de las artes plásticas en la construcción, sin buscar una verdadera correlación. Casi siempre se trataba de una superposición de la pintura en espacios preparados por los arquitectos, a manera de simple decoración. Sin embargo, una serie de profesionistas tanto en la edilicia como en la plástica, se opusieron a este tratamiento ofreciendo en la teoría y en la práctica una nueva proposición en la que el resultado fuese una total comunión de las artes. ${ }^{14}$ Todos están de acuerdo en que este tipo de resultado no es fácil de obtener y que

${ }^{10}$ Carlos Mérida fue en 1934 director del Departamento de Danza de la S.E P. (Margatita Nelken, op cit, p 31) y colaboró, entre 1941 y 1942, en El Mont Blanc College con algunos miembros del Bauhaus, como Walter Gropius, Lasslo-Moholy-Nágy y Josef Albers, y posteriormente en México con arquitectos como Mario Pani y Enrique del Moral

11 Ver por ejemplo los libros de Carlos Métida, Modern Mexican Aritists, Frescoes in Rodriguez Market, de 1937, y Frescoes in Primary Schools, de 1943, publicados, entre ottos por Frances Toor Estudios, México.

12 Ver "Conceptos plásticos", en el catálogo El Diseño, la Composición y la Integración Plásitica de Cáros Mérida, UNAM, México, 1963, p. 15. La primera vez que enunció este tipo de conceptos fue en una exposición en Nueva York en 1952; ver Mathías Goeritz, "La integración plástica en el CU. Presidente Juárez", Los multifamiliares de Pensiones, Editorial Arquitectura, México, 1952, p 104.

${ }^{13}$ Ibid.

14 Sobre este tema se han expresado entre otros Le Corbusier, Towards a New Architecture, Dover, New York, 1986 (de la edición 1931); Oscar Niemeyer y Paul Damaz, Art in Latin American Architecture, Reinhold Publishers, New York, 1963; Mathías Goetitz, op. cit., y el propio Carlos Mérida, ibid. 
demanda una real colaboración desde el principio de los diferentes participantes. Asimismo se coincide en afirmar que el único arte capaz de integrarse con la arquitectura contemporánea es aquel que se acerca a la abstracción por su simplicidad de líneas, cuyos inicios concordaron y propiciaron el movimiento actual de arquitectura.

En México la corriente del muralismo, de profundo contenido social y de expresión realista, monopolizó durante varias décadas la producción pública; estas obras, sin demérito de la calidad o del valor de sus autores, no lograron la deseada unidad con la edificación, conservando cada cual su independencia; se comprende entonces que los mejores ejemplos de esta tendencia estuviesen en los recintos eclesiásticos que utilizaron eminentemente motivos abstractos. Por ello Carlos Mérida, tanto por su estilo pictórico como por sus ideas de un arte universal sin barrèras, fue quien mejor logró integrarse en la corriente de arquitectura internacional. Asimismo debemos mencionar que los arquitectos con quienes colaboró tenían sus mismas ideas y aspiraciones, en especial Mario Pani, poseedor de una larga trayectoria de fructíferas realizaciones con diversos pintores. ${ }^{15}$

Esta nueva modalidad del artista guatemalteco se inicia en 1948, al lado del arquitecto Homero Martínez de Hoyos, con un relieve de piedra policromada para una casa en San Ángel; hoy en día se encuentra desgraciadamente recubierto. Martínez de Hoyos fue quien lo presentó con los arquitectos Mario Pani y Enrique del Moral, quienes por esa época proyectaban obras de gran envergadura. Juntos emprenden así una venturosa labor en común, misma que sólo se verá empañada por la destrucción que ha sufrido un número considerable de obras; este punto parece inverosímil, pero tiene su fundamento en la mencionada Ley de Monumentos que no contempla la protección de la obra artística de los extranjeros, y hasta diciembre de 1984 tampoco la de los arquitectos contemporáneos.

Así se explica que se retiraran los mosaicos de placas esmaltadas, que a manera de frisos adornaban el edificio de Recursos Hidráulicos, 1949, ante un extrañamiento del presidente de la República. ${ }^{16}$ Esta decoración, a la manera de platabandas, era de gran originalidad tanto por su realiza-

15. Mario Pani inició sú ielaciónín coñ artistas en el Hotel Reforma, con Diego Rivera, 1936, prosiguiendo en la Escuela Nacional de Maestros con José Clemente Orozco y Luis Ortiz Monastetio, 1947, y en la Torte de la Rectoría de la UNAM con David Alfato Siqueiros, 1952, entre otros

${ }^{16}$ En una entrevista con Matio Pani, a quien agtadezco su colabotación, me tefirió cómo al Ptesidente de la República, Miguel Alemán, le patecieton extrañas las deco. raciones del recién adquirido edificio de Recursos Hidráulicos, construido inicialmente para la Aseguradora Mexicana; el Secretario, Adolfo Oribe de Alba, los mandó quitar de inmediato 
ción en placas esmaltadas como por su diseño geométrico de inspiración prehispánica, el primer mural abstracto del arte mexicano. De la misma manera han desaparecido las pinturas que realizara en el friso de la guardería infantil del Multifamiliar Alemán, de las que tan sólo se conserva un motivo zoomorfo de los tres que adornaban el acceso de la guardería sin el menor mantenimiento o protección. ${ }^{17}$

Dentro de esta destrucción está el mural que realizó en masonite para el Museo Experimental "El Eco", 1950, puesto que este local también fue transformado. El caso del mural, curvo con aplicaciones policromadas, del bar "Los Eloines", 1950, es algo diferente, pues aunque ha sido retirado, se encuentra conservado en la Colección Alfa, de Monterrey, N.L. Si bien es de felicitarse por su salvaguarda, no puede dejar de lamentarse la pérdida de las condiciones originales, por la búsqueda de integración al espacio y a las necesidades existentes.

Sin embargo, el caso más decepcionante es el del Centro Multifamiliar "Benito Juárez", 1951-52, destruido hace un año, no tanto por el sismo del 19 de septiembre de 1985, como por la falta de conciencia estética por parte de los funcionarios gubernamentales. Éste había sido, de acuerdo a un consenso casi general, el mejor' ejemplo de integración plástica, "Una coordinación extraordinariamente feliz, de una integración rara vez obtenida... verdadera armonia". ${ }^{18}$ En esta ocasión arquitecto y pintor comprendieron que no debían imponerse, sino someterse, teniendo desde el principio del proyecto una relación de trabajo armonioso. Además, en esta obra Carlos Mérida utilizó como material básico el concreto, acertadamente, pues éste es por excelencia el material del siglo XX. "Arte del porvenir, sin demagogias, pero eminentemente universal. Arte para la masa, arte público a la vista de todos, para el goce emocional de todo el mundo". ${ }^{19}$ Así definió Mérida sus ideas, y en el amplio proyecto del Multifamiliar llevó a efecto uno de los más logrados ejemplos del arte que él denominaba funcional, y que se vuelve arte público por excelencia; los paneles se encontraban en las fachadas de algunos edificios, en las azoteas de otros, en las escaleras exteriores de algunos más, en la guardería infantil y finalmente en el paso a desnivel, como un acercamiento al automovilista y al públi-

17 Armando Colina, a quien manifiesto mi gratitud por sus informes, explica que Métida le nattó que sus pintutas se eliminaron a petición de José Clemente Orozco, quien iba a pintar un mural en un sitio contiguo. Mario Pani tan sólo recuerda que Orozco tenía una actitud sarcástica hacia Mérida.

${ }^{18}$ Mathías Goeritz, op cit , p. 104

19 Ibid. 
co en general. ${ }^{20}$ Para esta unidad habitacional, Carlos Mérida se inspiró en antiguas leyendas mexicanas tomadas del Popol-Vuh o de la Relación de Texcoco, temas que le eran caros. Así, ocho diosas del olimpo mexicano se reclinaban sobre los techos del edificio de trece pisos, y la leyenda de los cuatro soles se mostraban en los paneles de la fachada de los edificios de seis pisos, recubriendo exteriormente el sitio que ocupaban los closets; fueron las escaleras exteriores de cinco edificios altos las que mayor atractivo presentaban, y por las que dioses prehispánicos eternamente subían las escalinatas de un templo moderno. En la guardería, el muro del vestíbulo y una estela, en el jardín, ofrecían decoraciones adecuadas a su uso, realizadas en el mismo material, concreto policromado, pero finamente terminadas para poder ser apreciadas de cerca; en suma, se obtuvo un conjunto de expresiones murales unificadas en su expresión y temática, en apoyo a la coherencia e integración de las diversas edificaciones.

De una serie de murales que trabajó en varias casas particulares poco se sabe, salvo la diseñada por el arquitecto Víctor de la Lama, 1957, cuyo dueño, consciente del valor de la obra, al cambiarse de casa tomó el cuidado de llevarse el mural; en este caso es favorable conocer su conservación, aunque se haya perdido la liga original de la arquitectura y la pintura. El caso del mural del edificio de "Reaseguros Alianza", 1953, es similar, pues al ser destruido el edificio, los directores de la Galería Arvil lograron rescatarlo, y se conserva, aunque enrollado, en espera de un nuevo sitio para ofrecerse a los espectadores. También la fábrica de "Bujías Cham. pion", 1967, con un interesante proyecto en mosaico poblano de tonos blanco y azul, que pretendía demostrar cómo el uso de los materiales industriales abría una nueva posibilidad de obras al alcance de muchos, esta empresa donó, el 24 de marzo de 1987, el mural a la comunidad universitaria para su instalación en el Centro Cultural de la UNAM, en un sitio que el maestro Mérida ya había determinado.

Otro caso infortunado es el de la torre-insignia del conjunto urbano Nonoalco-Tlatelolco, conocida como la Torre BANOBRAS. En esta ocasión el problema radicó en la colocación de los mosaicos sobre un diseño de Carlos Mérida. ${ }^{21}$ El problema estuvo en la colocación, específicamente en

20 Afortunadamente descle 1963 los bocetos de estas obras, donados por su autor, son parte del acervo del Museo Universitario de Ciencias y Artes, donde han podido conservarse, Gaceta Universitaria, UNAM, México, agosto 19, 1985, p. 10.

${ }^{21}$ Mario Pani nos informó que en este caso no había para pagar a un artista, pero como Mérida ya había entregado su diseño, Pani simplemente lo mandó ejecutar, lo que el attista aceptó tácitamente y sin cobrar. Desde hace algún tiempo, Pani está pug. nando para que la torre recupere su aspecto original pintando sobre la cubierta actual los diseños originales. 
el "fino del cemento" que se puso bajo los mosaicos y que, por su grosor y la inclinación de los muros, comenzó a desprenderse. Los motivos tlatelolcas, de un tamaño adecuado al del edificio, eran gratamente percibibles, desde lejos, y sus formas se adaptaban a las aperturas incorporándolas en el diseño.

Finalmente cabe mencionar algunas edificaciones que han conservado la decoración mural, como el edificio de Crédito Bursátil, 1955, el antiguo edificio de la Industria Químico Farmacéutica, 1958, hoy Banco de Fomento Cooperativo, que resultó muy dañado en el sismo de 1985, pero en cuyo vestíbulo se localiza un interesante diseño en mosaico veneciano, y el edificio "Omega", 1985, de reciente factura y cuyas figuras de mosaico montadas en bastidores de metal fueron colocadas a los pocos días de la muerte de su diseñador. Asimismo, se tienen noticias de que la "Comisión Nacional Permanente para la exaltación de la obra del maestro Carlos Mérida", constituida en Guatemala, se ha propuesto conservar en buen estado la obra de este artista existente en su país natal. Una asociación que merece por su labor calurosas felicitaciones, en especial por haber sensibilizado al público en el respeto al arte.

"El problema de la decoración mural forma cuerpo, en unidad perfecta, con la arquitectura". ${ }^{22}$ Con esta frase Joaquín Torres García apunta en 1940 la verdadera problemática del arte público y enuncia los conceptos que una década más tarde asentará Carlos Mérida tanto en la teoría como en la práctica. Una vez más coinciden estos dos artistas defensores del americanismo y de la universalidad, y de alguna manera emiten ideas y proposiciones paralelas a través del tiempo y el espacio. ${ }^{23}$

Sin embargo, cabe anotar al artífice guatemalteco el honor de haber realizado una extensa labor artística, que cumple cabalmente con los presu-" puestos de la integración plástica. En sus proyectos se avocó desde el principio de sus actividades a tener una estrecha relación con los arquitectos, y el resultado formal se adaptó magníficamente a los espacios. El diseño, de simplicidad temática y geométrica, es asimismo compatible para su uso y comprensión en espacios públicos abiertos. Finalmente el uso de materiales eminentemente arquitectónicos como el mosaico, el mármol y el concreto responden a una profunda unidad en las artes. Carlos Mérida cumplió así no sólo con stus propios ideales, sino que fue también un artista que supo visualizar la problemática de un arte público, verdaderamente integrado,

22 Joaquín Torres García, op. cit, p, 788.

23 Joaquín Torres García realiza en 1938, en el Parque Rodó de Montevideo un "Momento Cósmico", a maneta de una gran estela de granito tosa tallado en relieve, similar en el tratamiento y espítitu a las tallas en piedra y concreto de Mérida. 
y que respondiera a las necesidades estéticas de los pueblos americanos. Su obra, vanguardista en un sentido, y local en otro, llenó el vacío que no pudo cubrir el arte del realismo socialista. Por ello se convirtió en precursor en la segunda mitad del siglo XX, teniendo un gran número de adeptos y seguidores. ${ }^{24}$

Por todas estas razones es aún más lamentable que la mayoría de los murales haya desaparecido, y así una parte de la historia del arte mexicano y universal se ha perdido por la incuria. Se hace necesario establecer normas para conservar lo que subsiste y, con base en el material documental, reconstruir en parte nuestro pasado artístico, y a la vez se ofrecerá así un homenaje póstumo a quien brindó a este país su saber y hacer, formando parte integral de la producción artística mexicana.

:En México, artistas como Manuel Felguérez derivan su obra de ésta, y en Guatemala existen ejemplos como el muto tealizado por Roberto González Goyri, cuyo relieve en piedra es llamado por Paul Damaz "estilo mexicano". Art in Latin American Archi tecture, Reinhold Publishers, New York, 1963, p. 113 


\section{MURALES EN MÉXICO}

\section{3}

Biblioteca Infantil, S.E.P.

Argentina y Luis González Obregón, México, D.F.

"La Caperucita Roja", "Los cuatro elementos"

Técnica: Dos tableros al óleo $\left(50\right.$ y $\left.30 \mathrm{~m}^{2}\right)$.

Estado actual: Desaparecido.

1948

Casa particular. Comedor.

Arturo 105, San Ángel, México, D.F.

Arquitecto: Homero Martínez de Hoyos.

"El encantador de pájaros".

Técnica: piedra tallada Xaltocan, policromada con silicón.

Estado actual: Recubierto.

\section{9}

Edificio Secretaría de Recursos Hidráulicos

Paseo de la Reforma, México, D.F.

Arquitectos: Mario Pani y Enrique del Moral.

Técnica: Frisos y platabandas en la fachada de mosaicos de placas metálicas esmaltadas a fuego.

Estado actual: Destruido.

1950

Bar "Los Eloines".

República de Cuba, México, D.F.

Técnica: Muro convexo de masonite con aplicaciones policromadas.

Estado actual: Retirado, expuesto en 1963 en una exposición en CU y adquirido por el grupo ALFA.

Museo Experimental "E1 Eco". Bar.

Sullivan, México, D.F.

Arquitecto: Mathías Goeritz.

Técnica: Formas de masonite policromadas.

Estado actual: Desaparecido.

Centro Multifamiliar "Miguel Alemán". Friso en la guardería infantil y figuras aisladas.

Av. Coyoacán y Félix Cuevas, México, D.F.

Arquitecto: Mario Pani.

Técnica: Pintura vinílica sobre concreto.

Estado actual: Destruido; sólo queda un motivo.

\section{1}

Centro Multifamiliar "Benito Juárez". Paneles exteriores, remates, escaleras, paso a desnivel, guardería infantil.

Jalapa y A. M. Anza, México, D.F. 
Arquitectos: Mario Pani y Salvador Ortega.

"Ocho diosas del olimpo mexicano", "Leyenda del origen del mundo, Popol Vuh", "Leyenda del Quinto Sol", "Leyenda del principio del mundo, Relación de Texcoco", "Leyenda de Ixtlexitl", "Leyenda de los Cuatro Soles", "Juego de niños".

Técnica: Relieves tallados en concreto coloreados parcialmente con vinilita. Estado actual: Casi totalmente destruidos (sismo de 1985); se conserva el paso a desnivel, la guardería y algunos páneles.

\section{3}

Edificios de Reaseguros "Alianza" "Vestíbulo.

Av. Insurgentes y Hamburgo, México, D.F.

Arquitecto: Enrique del Moral.

Técnica: Mosaico veneciano.

Estado actual: Edificio demolido (1980), el mural se conserva enrollado en la Galería Arvil.

Casa Particular Pasillo de acceso.

Lomas de Chapultepec, México, D.F.

Arquitecto: Víctor de la Lama.

Técnica: Concreto tallado y policromado.

Estado actual: Reinstalado actualmente en una casa en el Fraccionamiento Chiluca, Méx.

Casa Particular. Vestíbulo.

México, D.F.

Técnica: Mosaico veneciano.

Estado actual: Conservado. Propiedad del señor Santiago Bolaños.

1955

Fábrica de Helados "La Holanda".

Zaragoza y Corregidora, Monterrey, N.L.

Técnica: Mosaico veneciano.

Estado actual: Desaparecido

Fábrica de Mosaicos Italianos

Cerro Gordo, D.F.

Técnica: Mosaico de vidrio

Estado actual: Reinstalado en su nueva fábrica en Civac, Mor.

Edificio de Crédito Bursátil Exterior-Interior vestíbulo.

Isabel la Católica No. 44, México, D.F.

Arquitecto: Guillermo Struck.

Técnica: Mosaico veneciano

Estado actual: Conservado.

1958

Edificio de la Industria Químico-Farmacéutica, después Banco de Fomento Cooperativo Vestíbulo

Atenas y Versalles, México, D.F.

Arquitecto: Enrique del Moral 
Técnica: Mosaico veneciano.

Estado actual: Edificio dañado (sismo 1985), mural en peligro.

1963

Cine Manacar. Telón.

$A v$. Insurgentes y Río Mixcoac, México, D.F.

Arquitecto: Enrique Carral.

Técnica: Incrustaciones sobre madera.

Estado actual: Conservado.

1964

Torre de BANOBRAS. Muros exteriores.

Nonoalco, México, D.F.

Arquitecto: Mario Pani.

Técnica: Mosaico veneciano.

Estado actual: Destruido por la mala colocación.

Museo de Antropología, Sala Cora-Huichol,

Paseo de la Reforma y Gandhi, México, D.F.

Arquitectos: Pedro Ramirez Vázquez y Rafael Mijares.

"Los Adoratorios".

Técnica: Muro en vitral de acrílico.

Estado actual: Conservado.

1967

Fábrica de Bujías Champion. Exterior-Interior.

Calle 150 No. 956, Col. Industrial Vallejo, México, D.F.

Técnica: Mosaico en azulejo de Puebla.

Estado actual: Conservado, donado en marzo de 1987 a la UNAM para su reinstalación en el Centro Cultural Universitario.

1968

Hotel Aristos "Auditorio.

Paseo de la Reforma.

Técnica: Acrílico pulido sobre madera y oro de hoja.

Estado actual: Retirados y almacenados por el dueño.

1985

Edificio Omega. Vestíbulo.

Campos Elíseos No. 345, México, D.F.

Arquitecto: Pedro Ramírez Vázquez.

Técnica: Mosaico sobre marco metálico

Estado actual: Conservado. 
MURALES EN GUATEMALA*

1954

Casa particular. Vestíbulo.

Arquitecto: Krebs.

Técnica: Concreto policromado.

1955

Museo de Arqueologia. Panel.

Actualmente localizado en el Museo de Arte Moderno.

Técnica: Mosaico veneciano.

1956

Palacio Municipal . Vestíbulo y mezzanine.

Arquitectos: Pelayo Llarena y Roberto Aycinena.

"La raza mestiza" "

Técnica: Mosaico veneciano.

1958

Instituto Guatemalteco de Seguridad Social. Panel exterior.

Arquitectos: Jorge Montes y Roberto Aycinena.

Técnica: Mosaico veneciano.

Edificio de Oficinas. Mural exterior.

Arquitecto: Pelayo Llarena.

Técniea: Concreto policromado.

Casa particular. Exterior.

Arquitecto: Carlos Haeussler.

Técnica: Mosaico veneciano.

1963

Casa particular".

Arquitecto: Carlos Haeussler.

Técnica: Vitral.

Casa particular. Exterior-Interior.

Arquitecto: Jorge Molina.

Técnica: Mosaico veneciano. .

1965

Banco de Crédito Hipotecario. Vestíbulo.

Arquitectos: Jorge Montes, Raúl Minondo y Carlos Haeussler. Técnica: Mármol con placas de metal esmaltadas incrustadas. (Realizado por Franco Bucci, Italia.)

* Por no haber podido visitar estos sitios, no se describe el estado actual de esos murales, aunque se tiene conocimiento de que en Guatemala el "Círculo de amigas de Carlos Mérida" se ha preocupado por la conservación de los mismos. 
1966

Banco de Guatemala. Vestíbulo.

Arquitectos: Jorge Montes y Raúl Minondo.

Técnica: Mármol con placas de metal esmaltadas incrustadas

(Realizado por Franco Bucci, Italia).

\section{MURAL EN LOS ESTADOS UNIDOS*}

\section{8}

Centro de Convenciones. Hemisfair 1968.

Técnica: Mosaico veneciano.

San Antonio, Texas.

\section{PROYECTOS NO REALIZADOS}

Edificio en Lafragua y Paseo de la Reforma, México, D.F., 1949.

Arquitectos: Mario Pani y Jesús García Collantes.

Decoración: Vestíbulo y pisos de acceso a los elevadores.

Técnica: Terrazo y mosaico de piedra.

Banquetas del Paseo de la Reforma, México, D.F.

Técnica: Mosaico de mármol.

Se realizó una pequeña muestra, que estuvo técnicamente mal hecha; actualmente destruida. Los proyectos se encuentran en la Galería Arvil.

Aduana de Pantaco, México, D.F., 1953.

Arquitecto: Carlos Recamier.

Decoración: Murales exteriores.

Técnica: Concreto policromado.

Universidad Nacional Autónoma de México, México, D.F., 1953.

Arquitecto: Enrique de la Mora.

Decoración: Mural exterior en el Auditorio de la Facultad de Filosofía.

Técnica: Vítrex.

Hotel "Caleta", Acapulco, Gro., 1953.

Decoración: Mural en el hall.

Técnica: Concreto policromado.

Hotel "Vista Hermosa", México, D.F.

Decoración: Mural en el comedor.

Técnica: Vinilita.

Aeropuerto, México, D.F., 1956.

Arquitectos: Enrique Carral y Augusto H. Álvarez.

Decoración: Mural en el deambulatorio.

Técnica: Concreto policromado.

* Ver nota anterior 
Aeropuerto, Acapulco, Gro.

Arquitecto: Mario Pani.

Decoración: Celosías.

Casa particular, Cuernavaca, Mor.

Arquitectos: Víctor de la Lama, Ramón Torres y Héctor Velázquez.

Decoración: Murales exteriores.

Técnica: Mosaico veneciano.

Casa particular, México, D.F.

Arquitecto: Mario Pani.

Decoración: Mosaico con herrajes de hierro.

Proyectos para el Taller de los arquitectos Augusto H. Alvarez y Enrique Carral. 


\section{A P E N D I C E CONCEPTOS PLASTICOS DE CARLOS MÉRIDA (1953) *}

La pintura, en su estado actual, se encuentra en un callejón sin salida; seguirá teniendo vida precaria mientras no vuelva a su función natural. Ni el cuadro podrá seguir siendo cuadro, ni la escultura estatua.

La pintura contemporánea es toda invención; pero no llegará a su plenitud sino hasta que se canalice en pintura funcional. No hay otro camino.

La pintura de caballete, cosa del pasado. Arte para minorías. La pintura funcional, arte para mayorías.

El arte de nuestros días tiende a lo funcional. Ha encontrado ya su nombre: Arte de integración. Tal expresión, dice Mathías Goeritz, resume en una coordinación arquitectónico-plástica, todos los valores artísticos contemporáneos dentro de una unidad.

Pintura funcional, equivalente a pintura arquitectónico-mural.

El viejo concepto de muralismo mexicano (Montenegro, Rivera, Siqueiros, Orozco) ha dejado de ser, se comprenderá lo limitado de su concepto -aunque fecundo en muchos sentidos- si se piensa que fue gestado en momentos de crisis creativa y social, y acelerado por impaciencias más románticas que analíticas. De ahí parte el divorcio entre sus resultados y los edificios públicos en que fue ejecutada.

El arte toma otros derroteros; la vieja academia muralista no podrá detener la marcha hacia nuevas metas.

De nada servirá utilizar modernos materiales si las ideas son producto de tal academia. A nuevas ideas, nuevos materiales, y a la inversa.

La pintura hay que fundirla en el cuerpo arquitectónico y no tomarla como mera ornamentación. Éste es el muralismo que avizoramos.

Le Corbusier, patrono del funcionalismo, dijo: "La casa es la máquina para vivir"; Richard Neutra es más humano: "La casa es como una maceta en donde florece la familia”. ¿Por qué no aceptar aquella otra definición de Wright que dice: "La forma y la función no son más que una"? La pintura que preconizamos se acomodaría mejor con ella.

El "nuevo realismo" es un academismo disfrazado, sólo apto para caligrafías políticas; de uso inmediato. Este tipo de pintura, bueno para cartel, no puede convenir, ni concordar, con un arte desinteresado. La nueva pintura, es como la música: desinteresada.

* Tomados del catálogo de la exposición en 1963 en Ciudad Universitaria, El diseño, la composición y la integración plástica de Carlos Mérida, UNAM, México, 1963 


\section{BIBLIOGRAFIA}

América Latina en sus artes, relator Damián Bayón, Siglo Veintiuno Editores, México, 1974.

Bayón, Damián, Aventura Plástica de Hispano América, Fondo de Cultura Económica, México, 1974.

Brenner, Anita, idolos tras los Altares, Editorial Domés, México, 1983.

Carlos Mérida en sus 90 años, Cartón y Papel de México, México, 1981.

Cardoza y Aragón, Luis, Carlos Mérida, Ediciones de la Gaceta Literaria, Madrid, 1927.

Catlin, Stanton L y Terrence Grieder, Art of Latin America Since Independence, Yale University, Connecticut, 1986.

Damaz, Paul, Art in Latin American Architecture, Reinhold Publishers, New York, 1963.

Duncan, Barbara, Joaquín Torres García. 1874-1949, Universidad de Texas, Austin, 1975

Fernández, Justino, Estética del Arte Mexicano, UNAM, México, 1972.

- Pintura Moderna Mexicana, Pormaca, México, 1964.

Gamio, Manuel, Forjando Patria, Editorial Porrúa, México, 1960 (de la Edición de 1916), en especial el capitulo X, "El Concepto del Arte Prehispánico".

Luján Muñoz, Luis, Carlos Mérida, Cuadernos de Tradición Guatemalteca, Guatemala, 1985.

Manrique, Jorge Alberto, "El proceso de las Artes, 1910-1970", en Historia general de México, El Colegio de México, México, 1976.

Meyer, Lorenzo, "El primer tramo del camino", en Historia general de Mé. xico, El Colegio de México, México, 1976.

Mérida, Carlos, Modern Mexican Artists, Frances Toor Estudios, México, 1937.

-, Frescoes in Rodriguez Market, Frances Toor Estudios, México, 1937.

- Frescoes in Primary Schools, Frances Toor Estudios, México, 1943.

Moyssén, Xavier, "Los Mayores: Métida, Gerzso, Goeritz", El Geometrismo Mexicano, UNAM; México, 1977.

—_, "Tamayo, Mérida, Paalen y Gerzso", Historia del Arte Mexicano, Salvat, México, 1982.

Nelken, Margarita, Carlos Mérida, UNAM, México, 1961.

Pani, Mario, Los Multifamiliares de Pensiones, Editorial Arquitectura, México, 1952.

Pinocelly, Salvador, La obra de Enrique del Moral, UNAM, México, 1983.

Revilla, Manuel G., El arte en México, Porrúa Hermanos, México, 1923 (Primera edición, 1892).

Rodríguez Prampolini, Ida, "Las expresiones plásticas contemporáneas de México", Cuarenta Siglos de Arte Mexicano, Editorial Herrero, México, 1969. 
- "La figura del indio en la pintura del siglo XIX, fondo ideológico", La Iconografía en el Arte Contemporáneo, UNAM, México, 1982.

SuÁrez, Orlando S., Inventario del muralismo mexicano. UNAM, México, 1972.

Tibol, Raquel, Historia General del Arte Mexicano. Época Moderna y Contemporánea, Editorial Hermes, México, 1964.

Torres García, JoAquín, Universalismo constructivo, Editorial Poseidón, Buenos Aires, 1944.

\section{HEMEROGRAFİA Y CATÁLOGOS}

Arquitectura/México, No. 40, México, Diciembre 1952. En especial el artículo de Mathías Goeritz, "La Integración Plástica en el C.U. 'Presidente Juárez' ". Arquitectura/México, Nos. 94-95, México, Junio Septiembre 1966.

Carlos Mérida en sus sesenta años, Catálogo, Museo de Arte Moderno, México, 1962.

El diseño, la composición y la integración plástica de Carlos Mérida, Catálogo, UNAM, México, 1963.

Diseños de Carlos Mérida, Galería Arvil, México, 1981, Texto de Xavier Moyssén.

México en el Arte, No. 12, INBA, México, 1986. En especial el artículo de Tomás Zurian, "Ciudad destruida, rescate y restauraciơn".

Para esta investigación se realizaron entrevistas con el arquitecto Mario Pani el martes 3 de junio de 1986, con el licenciado Alfonso Soto Soria el miércoles 22 de octubre de 1986, y con el Señor Armando Colina el lunes 4 de agosto de 1986, y consultas con los arquitectos Hometo Martínez de Hoyos, Víctor de la Lama, Enrique del Moral e Hilario Galguera, y con la maestra Rita Eder, el profesor Xavier Moyssén y el doctor Mathías Goeritz. 